\title{
Investigation of The Amount of Energy Absorption of Aluminium Tube : Inversion and Concertina Collapse Mode
}

\author{
Mohd Suhairil Meon ${ }^{\mathrm{a}}$, Hazran Husain ${ }^{\mathrm{b}}$ \\ Faculty of Mechanical Engineering, Universiti Teknologi MARA, 40450, Shah Alam, Selangor, Malaysia \\ E-mail: ${ }^{a}$ msuhairil@salam.uitm.edu.my, ${ }^{b}$ hazran883@yahoo.co.uk
}

\begin{abstract}
The objective of this study is to investigate the effect of variation of the tube length and the crosshead velocity on the amount of energy absorption of aluminium tubes (Al 6061) towards the inversion and concertina collapsed mode. The tests were performed on the Aluminium tubes using compression test apparatus according to ASTM E8 standard procedures. Two parameters that are included in the experiment were the crosshead velocity and tube length. The collected experimental data were organized and analysis of energy absorption was performed. Comparison was made to the values of energy absorption obtained from the experiments, and it was found that the energy absorbed by the Aluminium tube under inversion mode was increased by increasing the tube length as well as crosshead velocity. Results for the concertina type mode differ with inversion mode.
\end{abstract}

Keywords — Energy absorption, inversion collapse mode, concertina collapse mode.

\section{INTRODUCTION}

Energy absorption devices are used in all vehicles and moving parts such as road vehicle, railway couches, aircraft, ships, lifts and machinery. The aim is to minimize injury to people and to confine the damage to properties [1]. Thin-walled metal tubes have been identified to be effective energy absorption structures and are frequently used as impact energy absorbers [2], [3].

Inversion tube is a simple energy absorber and capable to absorb high energy both in axial and compression modes. Basic concept of this particular process is by allowing a thin-walled ductile metal tube to be turned inside-out (external inversion) or outside-in (internal inversion) [4]. The thin-walled tube will be pushed against a special die that have appropriate fillet radius, it may then make the tube flow in inverse directions as illustrated in 0The large plastic strains involved in tube inversion limit its occurrence to ductile materials, such as steels and aluminium alloys, and to braided and filament wound composites, as discussed by Harte [5].

The concept of tube inversion can be extended if characteristics, stress-strain behaviour and deformation are fully understood and so many applications can be made based on this concept especially in safety devices. Recently, many applications on inversion tube concept have been made such as force actuating collapsible steering wheels, cushioning air drop cargo, helicopter seats and soft landing of spacecraft.

Alexander [6] performed an approximate analysis of the collapse of thin cylindrical shells under axial loading. He concluded that axial compression of tube through two flat plates will result in a progressive plastic folding behaviour. The shape of the fold depends on the dimension of the tube. Thicker tube tends to deform according to concertina collapse mode and the thinner tube more likely to form a diamond collapse mode. In some circumstances a combination of both modes may occur. An experimental study on the rate of energy absorption of aluminium alloy tubes under quasi-static loading was performed by Andrews [7]. As a result a classification chart has been produced that enable prediction on the energy absorbing characteristics and collapse mode for specific aluminium alloy tubes.

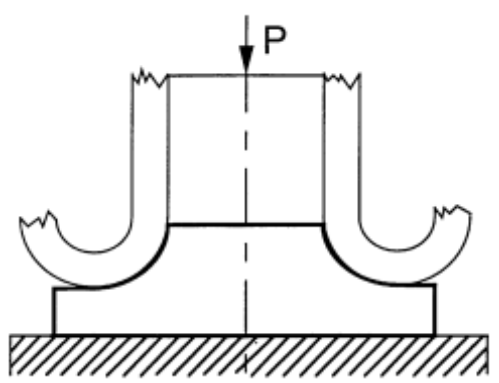

Fig. 1 Axial modes of collapse for cylinders: tube inversion [8] 
In this paper the rate of energy absorption of aluminium Al 6061 tube under inversion and concertina collapse mode are presented. The load-displacement curves were examined to investigate the effect of various cross-head velocity and tube length.

\section{EXPERIMENTS}

\section{A. Materials}

The material used for the specimens is Aluminium Alloy (Al 6061). The material obtained from Workshop Faculty of Mechanical Engineering, UiTM. The tubes are cut to different values of length varies from $70-110 \mathrm{~mm}$. The cutting process is performed using lathe machine to ensure that the end of the tube to be in square shape.

\section{B. Testings}

The experiments for the axial tube compression were carried out using INSTRON 3362 model. This machine is computer controlled hydraulic press will allow quasi-statics compressive loading to specimen with $100 \mathrm{kN}$ maximum load. All quasi-statics tests were performed in Strength and Materials Laboratory, Faculty of Mechanical Engineering, UiTM. The experimental set-up is sketched in Fig. 2 and Fig.3.

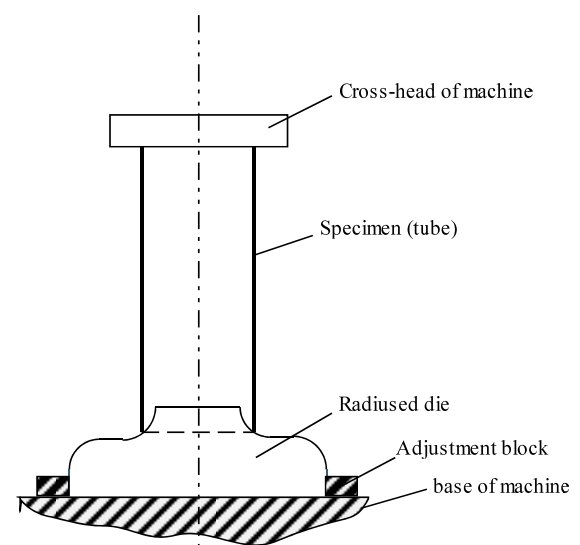

Fig. 2 Axial Sketch of quasi-statics experimental set-up: Inversion

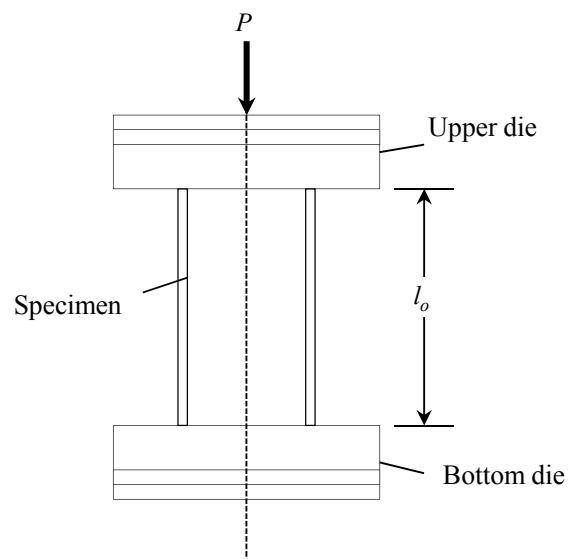

Fig. 3 Sketch of quasi-statics experimental set-up: Concertina

For the inversion collapse mode, the radiused die was fixed to the bottom bed of the testing machine. The photo of die used is illustrated in Fig.4.The die was made from mild steel, hardened and tempered to $45 / 55 \mathrm{HRc}$. Flat die is used for the concertina type of collapse as shown in Fig.5.

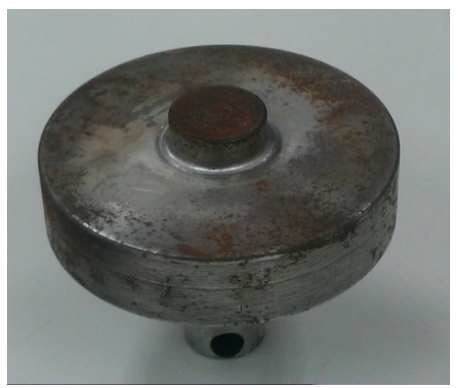

Fig. 4 Radiused die

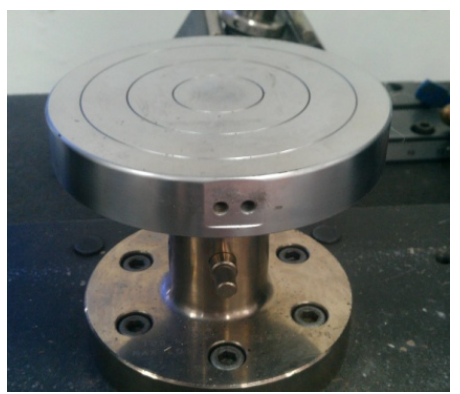

Fig. 5 Flat die

\section{Lubricant}

Friction plays a significant role to ensure the process of deformation of tube inversion to deform without buckling. Polytetrafluoroethylene (PTFE) was used during experiment to reduce the friction factor that may lead to the buckling. The surface die and inner area of the tubes has been lubricated with PTFE before conducting the experiments. PTFE is supplied by RS Components, Shah Alam.

\section{Quasi-statics Experiments}

The tube/cylinder shaped specimens were used in this experiments with initial dimension of inner diameter, $d_{i}=$ $35 \mathrm{~mm}$, wall thickness, $t=1.5 \mathrm{~mm}$ and also variation of length, $l_{o}=70,80,90,100,110 \mathrm{~mm}$. The details about the testing requirement indicated in Table 1. Both testing either inversion mode or concertina mode of collapse were experimented based on criteria in Table 1 .

TABLE I

SUMMARY OF TESTING REQUIREMENTS

\begin{tabular}{|c|c|c|}
\hline $\begin{array}{c}\text { Test ref. } \\
\text { no. }\end{array}$ & $\begin{array}{c}\text { Length of tube } \\
\text { (mm) }\end{array}$ & $\begin{array}{c}\text { Velocity of } \\
\text { cross-head } \\
\text { (mm/min) }\end{array}$ \\
\hline AL0701 & 70 & 5 \\
\hline AL0702 & 70 & 500 \\
\hline AL0801 & 80 & 5 \\
\hline AL0802 & 80 & 500 \\
\hline AL0901 & 90 & 5 \\
\hline AL0902 & 90 & 500 \\
\hline AL1001 & 100 & 5 \\
\hline AL1002 & 100 & 500 \\
\hline AL1101 & 110 & 5 \\
\hline AL1102 & 110 & 500 \\
\hline
\end{tabular}




\section{RESULTS AND DISCUSSIONS}

\section{A. Load-displacement Curve}

Fig.6 displays a load-displacement result obtained from the tests subjected to quasi-statics external inversion. Five points were highlighted in that graph showing point A until E. The points will be a point of the load to start rising, unsteady or steady state. The load has linearly risen from zero loads to the point A. During testing (from zero to point A), exhibits the end of tube start to flow and has contact with flaring radius. The inconsistency of the curve before reaching point $\mathrm{A}$ was caused by slip between tube and radius, since the die surface has been lubricated with PTFE. The load goes down rapidly to point $\mathrm{B}$ when the leading edge of the tube approaching the die surface which is at $180^{\circ}$ of angular displacement. As the compression continues, the load rises again up to point $\mathrm{C}$. The movement of the tube may cause the PTFE removed from the surface which increase the load at that point. Point $\mathrm{D}$ is the starting point for steady-state tube inversion zone. Further compression will contribute to the increment of load steadily until the leading tube has completed a total angular displacement.

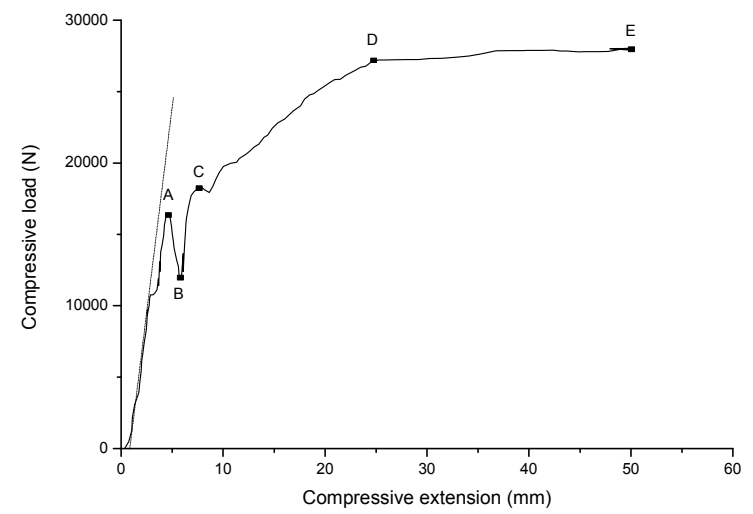

Fig. 6 Load-displacement curve for quasi-statics tube inversion

Fig.7 represents the load-displacement curve with deformation occurring at 5 different stages. The first stage is represented by Stage A where the buckling process due to three points of the tube has exceeded the yield point and turns the section element into plastic hinge. Stage B was the complete stage of concertina collapse mode. The process will repeat in stage $\mathrm{C}, \mathrm{D}, \mathrm{E}$ and so on.

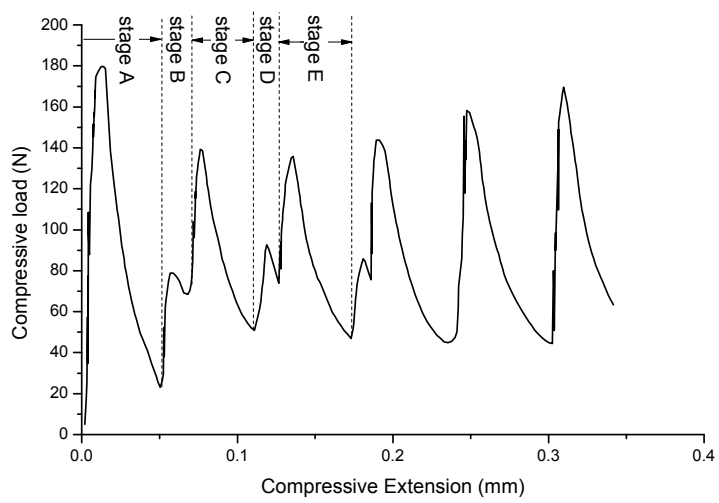

Fig. 7 Load-displacement curve for quasi-statics concertina mode

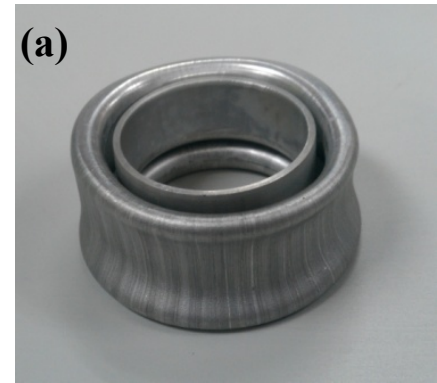

Fig. 8 Photo of specimen under Concertina collapse mode

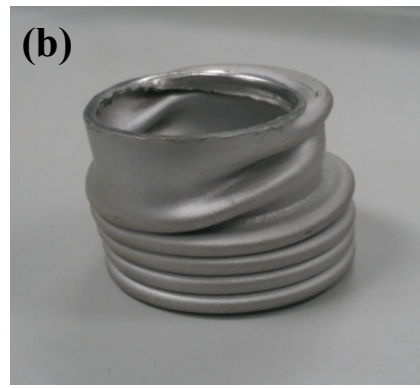

(a) Inversion collapse mode (b)

\section{B. Energy Absorbed by The Aluminium Tubes for Both Cases}

Results obtained in Fig.9 indicate that increasing the velocity cross-head and length of the tube can raise the energy absorption for inversion mode considerably. For example, compared with cross-head velocity of $5 \mathrm{~mm} / \mathrm{min}$ and $500 \mathrm{~mm} / \mathrm{min}$, the energy absorbed increases by about 7 $-15 \%$. It was suspected that the $500 \mathrm{~mm} / \mathrm{min}$ velocity give slightly higher energy absorption capacity due to fast compression mode applied to the specimens by accidentally removed the large amount of lubricant between die surface and the tube. Thus, the stress developed will increase when direct contact has occurred during experiments.

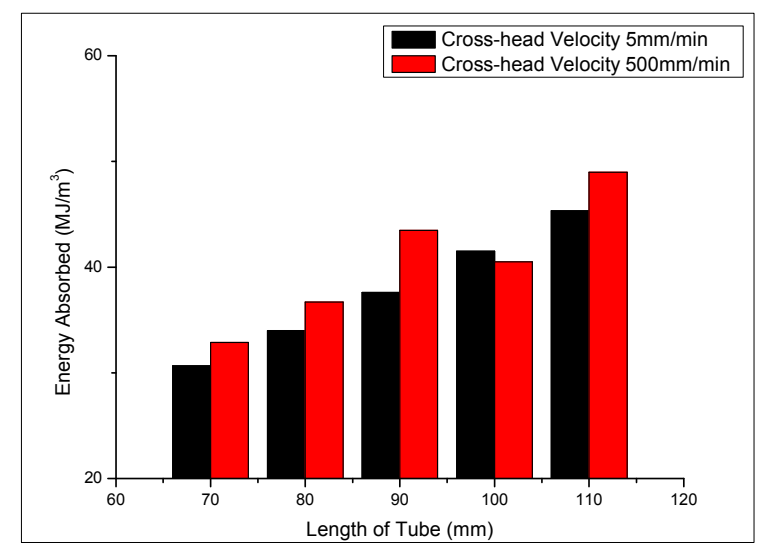

Fig. 9 Energy absorbed in inversion mode by the Aluminium tube in different cross-head velocity and length of tube

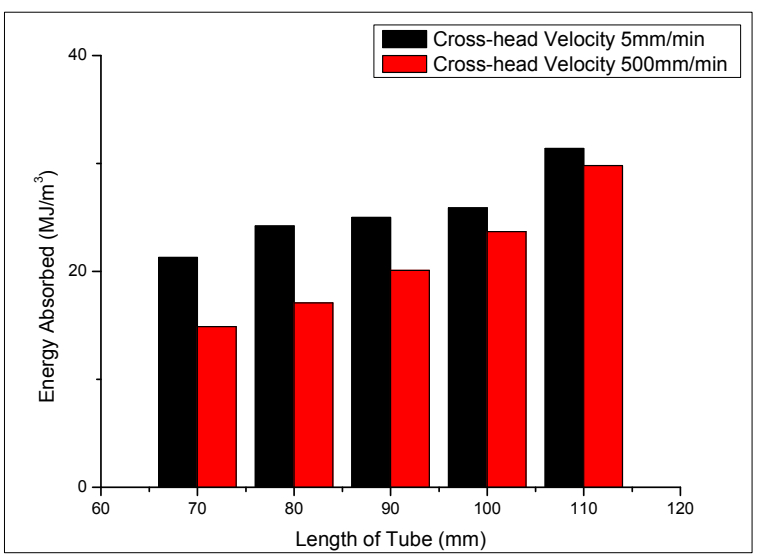

Fig. 10 Energy absorbed in Concertina mode by the Aluminium tube in different cross-head velocity and length of tube 
Fig.10 shows the rate of energy absorption with respect to the cross-head velocity and tube length. The amount of energy absorption was increased at low cross-head velocity and by increasing the tube length. Comparison on both modes with respect to $5 \mathrm{~mm} / \mathrm{min}$ and $500 \mathrm{~mm} / \mathrm{min}$ cross-head velocity also has been made as shown in Fig.11 and Fig.12. Higher energy absorption occurs on inversion collapse mode about $30-40 \%$ as compared to concertina collapse mode.

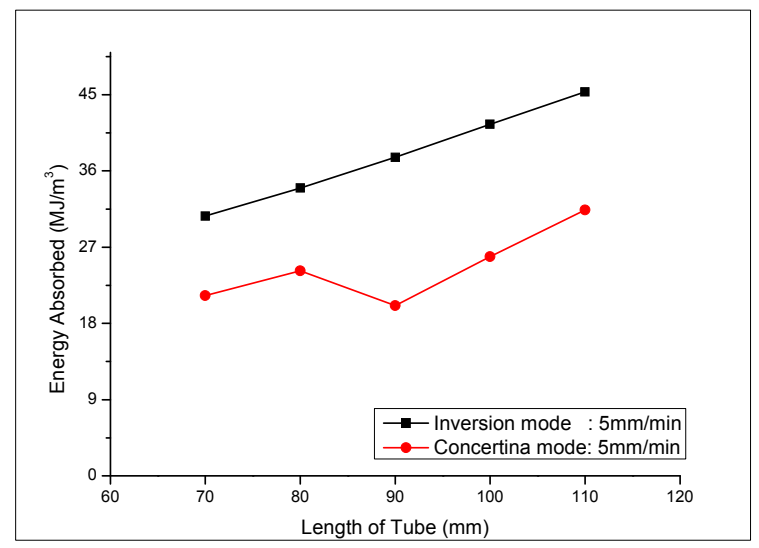

Fig. 11 Comparison of energy absorbed from both modes based on $5 \mathrm{~mm} / \mathrm{min}$ cross-head velocity

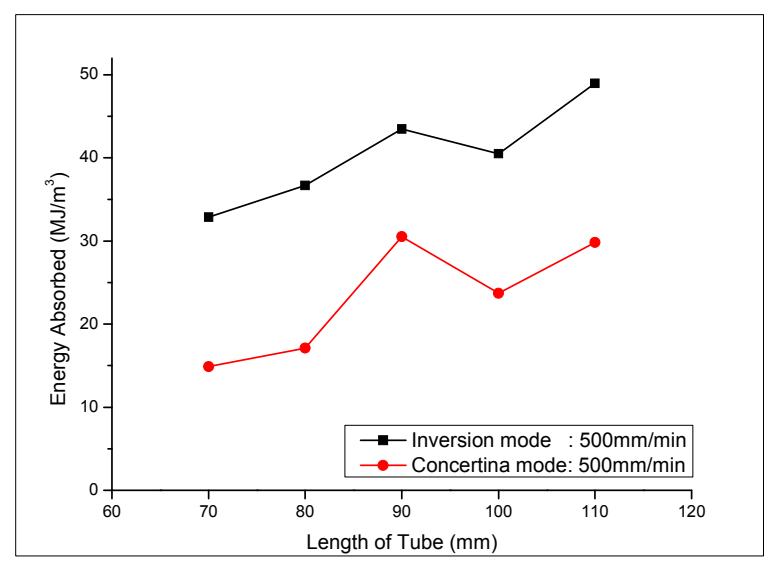

Fig. 12 Comparison of energy absorbed from both modes based on $500 \mathrm{~mm} / \mathrm{min}$ cross-head velocity

\section{Buckling of The Aluminium Tubes}

During the process of compression or crushing, buckling phenomena was occurred for the inversion collapsed mode. Fig.13 show that the buckling occurs during tube inversion process. Based on previous investigation, the buckling that occurs during inversion was known as local buckling and the buckling was caused by friction between the die surface and inner tube. Improper lubrication on die surface might expose the inner tube to certain area of die surface. However, the local buckling can be avoided by lubricating all possible area of contact, i.e. die surface and inner tube.

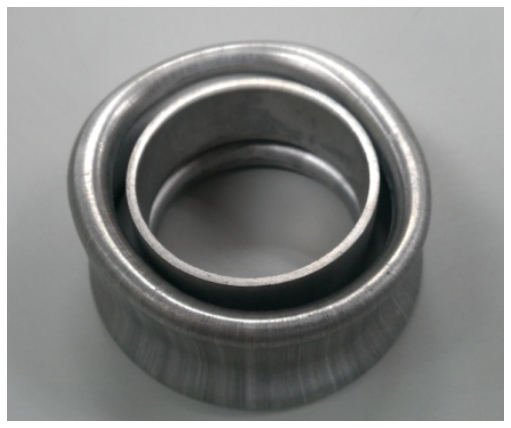

Fig. 13 Local buckling on Inversion tube: Top view

All the tube specimens under concertina collapse mode deformed in diamond shaped buckling as shown in Fig.14. It is attributed by the geometry imperfections and material non-linearity as agreed by George [9] and Guillow et al. [10].

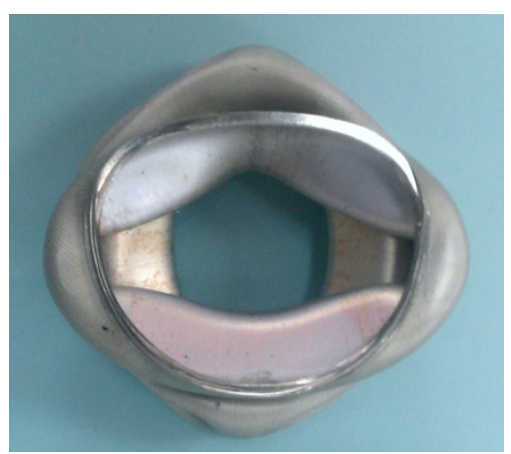

Fig. 14 Diamond shaped buckling

\section{CONCLUSION}

The Aluminium tubes (Al 6061) have been tested under compression test. The effects of changing two parameters which are cross-head velocity and length of tube on absorption of energy have been examined. The experimental approach chosen for this study is based on inversion collapse mode. Experimental results indicate that the energy absorbed based on inversion collapse mode was increased when increasing the amount of cross-head velocity and tube length but for concertina collapse mode, The amount of energy absorption was increased at low cross-head velocity and by increasing the tube length.Finally, the presence of friction at the die-tube interface significantly influences the energy absorption of Aluminium tubes as well as its deformation.

\section{ACKNOWLEDGMENT}

Special thank to Universiti Teknologi MARA, (UiTM) especially to Research Management Institute (RMI) UiTM and not to forget staffs at Strength of Materials Laboratory, Universiti Teknologi MARA UiTM. 


\section{REFERENCES}

[1] Hosseinipour, S.J., Daneshi, G.H.. Energy absorption and mean crushing load of thin-walled grooved tubes under axial compression, Thin-Walled Structures. Vol.41, pp31-46.2003

[2] Jones, N. Structural impact, Cambridge University Press, Cambridge, 1988

[3] Lu, G. and Yu, T. X. Energy Absorption of Structure and Material, Woodhead Publishing, Cambridge, 2003

[4] W. Johnson, Impact Strength of the Materials. Edward Arnold Limited., London, 1972

[5] Harte A.-M.,. "The mechanics of braided composites", $\mathrm{PhD}$ thesis, Cambridge University Engineering Dept, 1997

[6] J.M. Alexander, "An Approximate Analysis of the Collapse of Thin Cylindrical Shells under Axial Loading", Quart. J. Mech. Appl. Mat., pp. 10-16, 1960.

[7] Andrews, K .R.F., England, G .L. and Ghani, E., "Classification of the Axial Collapse of Cylindrical Tubes under Quasi-static Loading”, International Journal of Mechanical Science, Volume 25, Issues 9 -10, pp. 687-696, 1983.

[8] Anne-Marie Harte, Norman A. Fleck, Michael F. Ashby."Energy absorption of foam-filled circular tubes with braided composite walls",.Eur. J. Mech. A/Solids, Vol. 19 pp.31-50, 2000

[9] Sinitses George J., "Buckling and Post Buckling of Imperfect Cylindrical Shells: A Review", Applied Mechanics Review, Vol.39, pp.1517-1524, 1986.

[10] Guillow, S.R., Lu, G., Grzebeita, R.H. "Quasi-static Axial Compression of Thin Walled Circular Aluminium Tubes", International Journal of Mechanical Science, Vol. 43, pp.21032123, 2001

[11] Alghamdi, A.A.A., "Collapsible impact energy absorber: an overview".Thin-Walled Structures. Vol.39, pp.189-213., 2001.
[12] Birch, RS. and Norman Jones ,'Dynamics and static axial crushing of axially stiffened cylindrical Sells",Thin-Walled Structure, Vol.9, pp.29-60,1990

[13] Hanssen, A.G., langseth, M. and Hopperstad, O.S., "Static and dynamic crushing of circular aluminium extrusions with aluminium foam filler". International Journal of Impact Engineering. Vol. 24, pp.475-507.2000

[14] Miscow, P.C.F. and Al-Qureshi, H.A. "Mechanics of static and dynamic inversion process. ",International Journal of Mechanical Science,Vol.39, Issues 2, pp. 147-161,1997

[15] Reddy, T.Y. and Wall, RJ. , "Axial compression of foam-filled thin walled circular tubes", International Journal of Impact Engineering, Vol.7,issues 2,pp.151-166, 1988

[16] Reid, S.R., "Plastic deformation mechanisms in axially compressed metal tubes used as impact absorbers", International Journal of Mechanical Science, Vol. 35, issues 12, pp. 10351052,1993

[17] Reid, S.R. and Harrigan, J.J., "Transient effects in the quasistatic and dynamic internal inversion and nosing of metal tubes", Intemational Journal of Mechanical Science, Vol. 40, issues 2-3, pp. 263-280,1998

[18] Karagiozova, D., Jones, N., "On the Meechanics of the Global Bending Collapse of Circular Tubes under Dynamic Axial Load Dynamic Buckling Transition", International Journal of Impact Engineering., Vol.35, 397-424, 2008.

[19] N.K. Gupta and Nagesh, "Experimental and Numerical Studies of the Collapse of Thin Tubes under Axial Compression", Latin American Journal of Solids and Structures, Vol. 1, 233-260, 2004.

[20] Abramowicz, W., Jones, N., "Dynamic Axial Crushing of Circular Tubes”, Int. J. Impact Engineering, Vol. 2, 263-281, 1984.

[21] Abramowicz, W., Wierzbicki, T., "On the Crushing Mechanics of Thin-Walled Structures", Int. J. Appl. Mech, 157-174, 1986. 